\title{
Kemampuan Mahasiswa Calon Guru Biologi dalam Menyusun Scientific Papers
}

\author{
Setiono ${ }^{a}, 1^{\star}$, Nuryani Y Rustaman ${ }^{\mathrm{b}}$, Adi Rahmat ${ }^{\mathrm{b}}$, Sri Anggraeni ${ }^{\mathrm{b}}$ \\ ${ }^{a}$ Pendidikan Biologi FKIP, Universitas Muhammadiyah Sukabumi, J1. R. Syamsudin SH No 50 Kota Sukabumi 43113, Indonesia

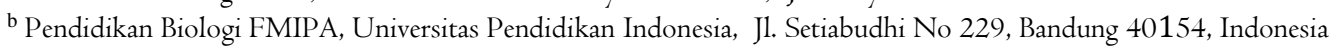 \\ 1 setionoase@gmail.com* \\ *korespondensi penulis
}

\begin{abstract}
ABSTRAK
Kemampuan menyusun scientific papers dari hasil penelitian merupakan salah satu kemampuan dasar yang harus dimiliki oleh mahasiswa. Penelitian ini bertujuan untuk mengetahui kemampuan mahasiswa calon guru biologi dalam menyusun scientific papers hasil investigasi di laboratorium. Penelitian ini dilakukan pada mahasiswa calon guru biologi $(\mathrm{n}=15)$. Instrumen yang digunakan dalam penelitian ini berupa lembar observasi kemampuan membuat scientific papers dan pedoman wawancara. Adapun aspek yang dinilai dari kemampuan membuat scientific papers: mengonstruksi judul, membuat abstrak, menyusun pendahuluan, merancang metodologi penelitian, menyajikan hasil penelitian, menyajikan gambar yang ditampilkan, pembahasan dan kualitas sitasi yang digunakan di dalam scientific papers. Hasil penelitian menunjukkan bahwa kemampuan mahasiswa dalam membuat scientific papers masih rendah, hal tersebut dapat dilihat dari rata-rata persentase penguasaan kemampuan yang hanya 31\%. Perlu ada upaya untuk mengembangkan kemampuan ini yang terintegrasi dengan program perkuliahan dalam upaya untuk mengembangkan kemampuan membuat scientific papers mahasiswa.
\end{abstract}

Kata kunci: calon guru biologi, investigasi, scientific papers

\section{ABSTRACT}

The ability to construct a scientific papers from is one of the basic skills that must be owned by students. This study aims to determine the ability of prospective biology teacher in construct scientific papers of laboratory investigation. This research was conducted on prospective biology teacher $(n=15)$. The instrument used in this research is an observation sheet of the ability to construct a scientific papers. The aspects assessed from the ability to create a scientific papers are: ability to construct the title, to make an abstract, to prepare a preliminary, to design a research methodology, to present the results of research, to present the displayed images, the discussion and the quality of citation used in scientific papers. The results showed that the ability of students in construct scientific papers is still low, it can be seen from the average percentage of mastery skills that only $31 \%$. There needs to be an effort to develop this capability that is integrated with the lecture program in an effort to develop students' scientific writing skills.

Keyword: investigation, prospective biology teacher, scientific papers

Copyright (C) 2017 Universitas Ahmad Dahlan. All Right Reserved

\section{Pendahuluan}

Kemampuan berkomunikasi dalam bentuk tulisan ilmiah merupakan kemampuan penting yang harus dimiliki oleh mahasiswa di perguruan tinggi (Susanne Pelger \& Nilsson, 2016; Susanne Pelger \& Santesson, 2012). Keterampilan menulis karya ilmiah merupakan salah satu kemampuan dasar yang harus dimiliki oleh mahasiswa dalam rangka memenuhi tuntutan-tuntutan akademik dan learning outcome selama masa perkuliahan di perguruan tinggi. Keterampilan menulis karya ilmiah juga penting bagi masyarakat akademik di perguruan tinggi dalam rangka mengembangkan bidang keilmuan yang ditekuni oleh mahasiswa (S Pelger, Santesson, \& Josefsson, 2009). Pembelajaran di perguruan tinggi tidak hanya semata kegiatan pembelajaran yang berupa transfer keilmuwan saja tetapi harus disertai dengan pengembangan dan reproduksi keilmuan baru (Tonissen, Lee, Woods, \&
Osborne, 2014). Salah satu bentuk karya ilmiah yang harus dibuat oleh mahasiswa adalah artikel ilmiah hasil penelitian atau dikenal dengan scientific papers. Keterampilan menyusun karya tulis ini harus dimiliki oleh mahasiswa karena salah satu tuntutan saat menempuh tugas akhir mahasiswa harus melakukan publikasi hasil penelitiannya dalam bentuk artikel ilmiah. Selain itu, kemampuan ini juga akan membantu mahasiswa dalam mengembangkan diri ketika mereka terjun di dunia kerja menjadi pendidik (Susanne Pelger \& Santesson, 2012).

Keterampilan mengonstruksi scientific papers atau artikel ilmiah merupakan kemampuan yang harus dimiliki oleh mahasiswa, termasuk mahasiswa calon guru biologi, kemampuan menyusun scientific papers menjadi bagian dari kompetensi dasar yang harus dimiliki oleh mahasiswa. Selain itu, kemampuan membuat scientific papers menjadi bagian dari kemampuan mengomunikasikan hasil penelitian atau kajian yang telah dilakukan. 
Mahasiswa dituntut untuk dapat berkomunikasi ilmiah dengan efektif seperti halnya seorang ilmuwan, sehingga informasi yang dipublikasikan dapat memberikan informasi yang bermakna dan bermanfaat.

Mahasiswa dalam menyusun karya ilmiah dalam bentuk scientific papers harus memiliki kemampuan dan keterampilan khusus. Mahasiswa harus memiliki pengetahuan dan kemampuan menggunakan logika (nalar) agar dapat menyusun scientific papers dengan baik (Susanne Pelger \& Nilsson, 2016). Scientific papers yang dibuat biasanya terdiri atas judul, abstrak, pendahuluan yang berisi latar belakang masalah dan tinjauan kepustakaan, metodologi penelitian, hasil dan pembahasan, kesimpulan dan sitasi hasil penelitian. Penyajian setiap aspek pada scientific papers ini perlu pengetahuan dan kemampuan menggunakan logika yang baik, misal ketika mengonstruksi judul, judul harus dibuat menarik dalam arti menarik pembaca untuk mengelaborasi isi dari karya tulis yang ditulis.

Kemampuan mengomunikasikan informasi dalam bentuk tulisan menjadi bagian penting dalam praktik pengajaran sains yang harus dimiliki oleh mahasiswa. Standar praktik pengajaran sains di Amerika menyebutkan bahwa salah satu praktik pengajaran sains yang harus dilakukan oleh siswa adalah mengomunikasikan informasi (National Research Council, 2012). Kemampuan mengomunikasikan informasi dalam bentuk karya tulis ilmiah merupakan kemampuan yang sulit untuk diajarkan kepada mahasiswa, hal ini dibuktikan dengan kemampuan rata-rata mahasiswa di lapangan yang masih rendah (Susanne Pelger \& Nilsson, 2016). Pada standar pengajaran sains di Amerika disebutkan bahwa pengajaran sains harus meliputi beberapa pengalaman belajar diantaranya: 1) Asking questions and defining problems, 2) Developing and using models, 3) Planning and carrying out investigations, 4) Analyzing and interpreting data, 5) Using mathematics and computational thinking, 6) Constructing explanations and designing solutions, 7) Engaging in argument from evidence, dan 8) Obtaining, evaluating, Communicating (Ziker, 2014).

Tujuan dari penelitian ini adalah memperoleh gambaran tentang keterampilan mahasiswa dalam menyusun karya tulia ilmiah dalam bentuk scientific papers dan mengetahui kendala serta permasalahan yang mahasiswa hadapi ketika menyusun scientific papers. Kemampuan ini penting diketahui sejak dini agar dosen dapat menyiapkan pengalaman belajar dan memiliki waktu yang cukup untuk mengembangkan kemampuan menyusun scientific papers.

\section{Metode Penelitian}

Penelitian ini dilaksanakan di Program Studi Pendidikan Biologi. Waktu pelaksanaannya adalah pada semester ganjil tahun ajaran 2015/2016. Subjek penelitian adalah mahasiswa yang mengambil mata kuliah Praktikum Anatomi Tumbuhan sejumlah 15 orang. Objek penelitiannya adalah artikel yang dibuat oleh mahasiswa sebagai tugas akhir pada mata kuliah Praktikum Anatomi Tumbuhan. Penelitian ini merupakan penelitian kualitatif yang bertujuan untuk menjelaskan fenomena masalah yang dialami mahasiswa dalam membuat karya berupa scientific papers hasil miniriset pada praktikum Anatomi Tumbuhan. Data penelitian berupa scientific papers mahasiswa yang dianalisis secara deskriptif dan kualitatif.

Pengumpulan data dilakukan melalui lembar observasi keterampilan menyusun scientific papers dan pedoman wawancara dengan mahasiswa. Data hasil penelitian kemudian dianalisis dan dibandingkan dengan indikator keberhasilan yang telah ditentukan sebelumnya. Parameter yang digunakan untuk melihat ketercapaian keterampilan menyusun scientific papers disusun berdasarkan parameter ketercapaian yang telah ditetapkan berdasarkan kriteria ketercapaian menurut Arikunto (2008) sebagaimana tersaji pada tabel 1 , penentuan nilai persentase skor dengan menggunakan rumus sebagai berikut:

\begin{tabular}{|c|c|}
\hline $\begin{array}{l}P s=\frac{s}{N} X 100 \% \\
\text { Keterangan: } \\
\text { Ps = Persentase Skor } \\
S=\text { Skor yang diperoleh } \\
\mathrm{N}=\text { Jumlah skor maksimur } \\
\text { Tabel I. Kriteria nilai per }\end{array}$ & etiap komponen \\
\hline Persentase Skor (\%) & Kategori \\
\hline $\begin{array}{c}81-100 \\
61-80 \\
41-60 \\
\leq 21\end{array}$ & $\begin{array}{l}\text { Baik sekali } \\
\text { Baik } \\
\text { Cukup } \\
\text { Kurang }\end{array}$ \\
\hline
\end{tabular}

\section{Hasil dan Pembahasan}

Penelitian ini dilakukan dengan melakukan studi dan observasi terhadap dokumen karya ilmiah dalam bentuk scientific papers yang dibuat oleh mahasiswa setelah melakukan praktikum anatomi tumbuhan. Penilaian dilakukan berdasarkan kualitas pada setiap aspek penilaian scientific papers yang dibuat. Aspek yang dinilai meliputi: 1) Judul, 2) Abstrak, 3) Pendahuluan, 4) Metodologi, 5) Hasil Investigasi, 6) Gambar dan tabel, 7) Pembahasan dan 8) Sitasi Literatur (Jenkins, 1997). Hasil penskoran setiap aspek penilaian scientific papers dapat dilihat pada tabel 2 . 
Tabel 2. Perolehan skor hasil penilaian scientific papers

\begin{tabular}{|c|c|c|c|c|c|c|c|}
\hline \multirow{2}{*}{ Aspek Penilaian } & \multirow{2}{*}{ Indikator Penilaian } & \multicolumn{4}{|c|}{ Kelompok } & \multirow{2}{*}{ JML } & \multirow{2}{*}{$\begin{array}{l}\text { Persentase } \\
\text { Penguasaan } \\
\text { (\%) }\end{array}$} \\
\hline & & 1 & 2 & 3 & 4 & & \\
\hline Judul & $\begin{array}{l}\text { judul jelas, menggambarkan isi, informatif dan } \\
\text { dapat dipahami dengan baik (tidak ada } \\
\text { pengulangan kata, padat) }\end{array}$ & 3 & 2 & 3 & 1 & 9 & 56,25 \\
\hline Abstrak & $\begin{array}{l}\text { abstrak menjelaskan secara ringkas tentang } \\
\text { signifikansi masalah, tujuan, metode, hasil, dan } \\
\text { kesimpulan }\end{array}$ & 1 & 1 & 1 & 1 & 4 & 25,00 \\
\hline Pendahuluan & $\begin{array}{l}\text { Terdapat penjelasan latang belakang masalah } \\
\text { yang jelas, permasalahan, pertanyaan penelitian } \\
\text { atau hipotesis }\end{array}$ & 0 & 1 & 0 & 0 & 1 & 6,25 \\
\hline Metodologi & $\begin{array}{l}\text { Terdapat penjelasan desain penelitian dan } \\
\text { prosedur penelitian yang dinyatakan dengan } \\
\text { tepat dan jelas }\end{array}$ & 1 & 1 & 2 & 2 & 6 & 37,50 \\
\hline Hasil investigasi & $\begin{array}{l}\text { Terdapat penyajian hasil yang berupa deskripsi, } \\
\text { gambar, ilustrasi dan tabel hasil pengamatan }\end{array}$ & 1 & 1 & 1 & 1 & 4 & 25,00 \\
\hline Gambar dan tabel & $\begin{array}{l}\text { Gambar yang disajikan memiliki keterangan } \\
\text { yang jelas tepat dan proporsional }\end{array}$ & 1 & 2 & 1 & 1 & 5 & 31,25 \\
\hline Pembahasan & $\begin{array}{l}\text { Pembahasan memperlihatkan hasil analisis, } \\
\text { interpretasi dan jawaban pertanyaan penelitian } \\
\text { yang jelas, tepat dan relevan }\end{array}$ & 1 & 2 & 1 & 1 & 5 & 31,25 \\
\hline \multirow{2}{*}{ Sitasi literatur } & $\begin{array}{l}\text { Sumber pustaka yang digunakan merupakan } \\
\text { sumber yang mutakhir }\end{array}$ & 1 & 2 & 2 & 2 & 7 & 43,75 \\
\hline & $\begin{array}{l}\text { Terdapat kurang lebih } 5 \text { sitasi yang merupakan } \\
\text { sumber primer }\end{array}$ & 1 & 1 & 1 & 1 & 4 & 25,00 \\
\hline \multicolumn{2}{|r|}{ Rata-Rata } & & & & & & 31,32 \\
\hline
\end{tabular}

papers, skor rata rata memperlihatkan bahwa keterampilan mahasiswa calon guru biologi dalam membuat scientific papers berada pada kategori tidak baik. Hasil analisis kategori keterampilan mahasiswa dalam membuat scientific papers tersaji pada gambar 1, dari delapan aspek yang diukur hanya aspek pembuatan judul yang telah memenuhi kategori baik, selebihnya masuk pada kategori kurang, bahkan pada aspek menyusun pendahuluan scientific papers diperoleh hasil paling rendah dengan nilai 6,25 .

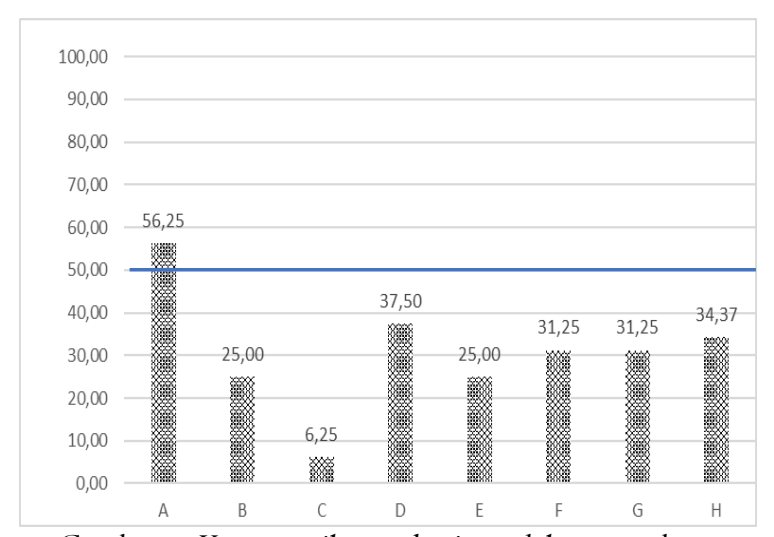

Gambar I. Keterampilan mahasiswa dalam membuat scientific papers dengan aspek (A) Judul, (B) Abstrak, (C) Pendahuluan, (D) Metodologi, (E) Hasil investigasi, (F)
Hasil penelitian menunjukan bahwa mahasiswa masih mengalami banyak kendala ketika ditugaskan untuk menyusun scientific papers. Kemampuan menulis scientific papers merupakan kemampuan yang harus didukung oleh kemampuan lainnya seperti kemampuan menalar, metakognitif, pengetahuan yang mumpuni dan kemampuan lainnya. Apabila kemampuan pendukung tersebut tidak dimiliki maka mahasiswa akan mendapatkan banyak kendala ketika ditugaskan untuk menyusun scientific papers.

Kemampuan menyusun atau mengonstruksi scientific papers merupakan kemampuan esensial yang harus dimiliki oleh mahasiswa. Kepercayaan diri harus dibangun sebagai salah satu modal dasar bagi mahasiswa untuk menuliskan hasil studinya dalam bentuk karya tulis ilmiah (Sanders-Reio, Alexander, Reio, \& Newman, 2014). Selain itu, perlu kemampaun nalar (reasoning) dan pengetahuan yang yang baik agar dapat menyusun scientific papers dengan baik (Cronje, Murray, Rohlinger, \& Wellnitz, 2013; Dysthe, Hertzberg, \& Hoel., 2011; Susanne Pelger \& Nilsson, 2016). Kemampuan nalar yang kurang dan pengetahuan yang terbatas akan menyulitkan mahasiswa dalam menyusun scientific papers. Hasil pengukuran nalar mahasiswa yang 
dilakukan peneliti terhadap mahasiswa yang mengikuti mata kuliah Praktikum Anatomi Tumbuhan menunjukan bahwa kemampuan nalar mahasiswa masih tergolong rendah (Setiono, 2016).

Kemampuan nalar mahasiswa yang rendah ini akan menjadi hambatan tersendiri bagi mahasiswa ketika menyusun scientific papers. Menyusun scientific papers menuntut mahasiswa untuk mengungkapkan latar belakang penelitian, merumuskan pertanyaan penelitian, merumuskan hipotesis, merancang dan melaksanakan percobaan, menganalisis data serta menginterpretasikannya, serta mengonstruksi kesimpulan. Kemampuan menyusun scientific papers juga dipengaruhi oleh pengetahuan yang dimiliki oleh mahasiswa, apabila mahasiswa menguasai pengetahuan yang mumpuni terkait dengan apa yang sedang dikaji, maka akan memudahkan mahasiswa dalam menyusun scientific papers (Susanne Pelger \& Nilsson, 2016).

Hasil wawancara dengan mahasiswa diperoleh informasi bahwa selama ini mahasiswa mengalami kesulitan dalam menyusun karya tulis dalam bentuk scientific papers karena mereka belum terbiasa membuat karya tulis dalam bentuk scientific papers. Mahasiswa juga tidak terbiasa membaca karya tulis dalam bentuk scientific papers. Sehingga mereka tidak mengetahui kerangka pikir dalam menyajikan karya tulis ilmiah. Selain itu, mahasiswa juga belum memahami hakikat dari setiap komponen yang harus ada dalam sebuah scientific papers seperti: menyajikan pendahuluan, menyajikan latar belakang penelitian, menyajikan metodologi penelitian serta menyajikan hasil dan pembahasan hasil penelitian.

Pembiasaan merupakan metode pembelajaran yang penting dilakukan untuk membentuk suatu kemampuan tertentu (Barrie, 2007). Pembiasaan dapat dilakukan untuk mengembangkan kemampuan tertentu misalnya kemampuan mengonstruksi scientific papers. Pembiasaan terhadap mahasiswa untuk mengonstruksi dan membaca, menganalisis sebuah scientific papers dapat membantu mengembangkan kemampuan mahasiswa dalam mengonstruksi scientific papers.

Kemampuan mengonstruksi scientific papers merupakan bagian dari kemampuan berkomunikasi tulisan yang penting dikuasai oleh mahasiswa. Menurut Walsh (2010) kemampuan menulis ilmiah menjadi bagian yang tidak terpisahkan dan penting dalam keterampilan akademis serta merupakan aset yang berharga bagi karir mahasiswa. Kemampuan mengonstruksi scientific papers dapat dikembangkan salah satunya dengan memberikan penugasan kepada mahasiswa untuk membuat karya tulis dalam bentuk scientific papers (Iftanti, 2016). Penugasan membuat scientific papers kepada mahasiswa juga dapat memberikan pengalaman dan pembiasaan kepada mahasiswa yang pada akhirnya dapat mengembangkan kemampuan mahasiswa dalam mengembangkan karya tulis ilmiah dalam bentuk scientific papers. Strategi perkuliahan perlu dibertimbangkan agar dapat mengembangkan kemampuan menulis karya tulis. Kemampuan menulis memerlukan kemampuan nalar dan metakognitif yang cukup, sehingga dosen perlu menciptakan pengalaman belajar yang dapat mengembangkan nalar dan kemampuan metakognitif mahasiswa. Model pembelajaran project based learning (PjBL) merupakan salah satu model pembelajaran yang dapat diimplementasikan untuk mengembangkan kemampuan mahasiswa dalam menulis karya ilmiah (Indriani, Widoretno, \& Dwiastuti, 2017).

Metode assessment juga perlu dipertimbangkan ketika mahasiswa menyusun scientific papers (Susanne Pelger \& Nilsson, 2016). Umpan balik yang diberikan oleh dosen terhadap scientific papers yang disusun oleh mahasiswa dapat menciptakan pengalaman belajar yang berarti bagi mahasiswa. Umpan balik yang diberikan dosen dapat memperbaiki kesalahan-kesalahan serta kekurangan yang dibuat oleh mahasiswa ketika menyusun scientific papers.

Kemampuan nalar mahasiswa (reasoning), pengetahuan mahasiswa, pembiasaan menyusun scientific papers serta metode assessment merupakan beberapa hal yang perlu dipertimbangkan ketika ingin mengembangkan kemampuan menyusun scientific papers. Pengalaman belajar pun perlu dipertimbangkan agar mahasiswa mendapatkan pengalaman belajar yang cukup sehingga mahasiswa dapat mengembangkan kemampuan ini dengan maksimal.

\section{Simpulan}

Hasil Penelitian menunjukkan bahwa keterampilan mahasiswa calon guru biologi dalam menyusun scientific papers masih dalam kategori kurang. Hal ini menjadi masukan dan rekomendasi bagi dosen dan stakeholder terkait untuk dapat meningkatkan keterampilan mahasiswa dalam menyusun scientific papers. Ada beberapa pertimbangan yang perlu dosen ketahui untuk mengembangkan kemampuan menyusun scientific papers diantaranya: nalar mahasiswa, pengetahuan mahasiswa, pengalaman belajar serta metode assessment yang tepat. Kemampuan menyusun scientific papers penting dimiliki oleh mahasiswa dalam rangka untuk mengembangkan bidang keilmuan yang ditekuni yang pada akhirnya akan memberikan dampak positif bagi pengembangan 
ilmu pengetahuan dan karir mahasiswa itu sendiri ketika mereka sudah terjun di dunia kerja.

\section{Daftar Pustaka}

Arikunto, S. (2008). Evaluasi Program Pendidikan (Pedoman Teoretis Praktis Bagi Mahasiswa dan Praktisi Pendidikan. Jakarta: Bumi Aksara.

Barrie, S. C. (2007). A conceptual framework for the teaching and learning of generic graduate attributes. Studies in Higher Education, 32(4), 439-458. https://doi.org/I0.1080/03075070701476 IOO

Cronje, R., Murray, K., Rohlinger, S., \& Wellnitz, T. (20I3). Using the Science Writing Heuristic to Improve Undergraduate Writing in Biology. International Journal of Science Education, 35(16), 2718-273I.

https://doi.org/I0.1080/09500693.201 1.6 28344

Dysthe, O., Hertzberg, F., \& Hoel., T. L. (20I I). Skriva för att lära [Writing to Learn]. Lund: Studentlitteratur.

Iftanti, E. (2016). Improving Students' Writing Skills Through Writing Journal Articles. IAIN Tulungagung Research Collections, 8(I), I22.

Indriani, A., Widoretno, S., \& Dwiastuti, S. (2017). Case: Quality of Student's Content Writing Through Implementation of Project Based Learning Model in Biology. JURNAL BIOEDUKATIKA, 5(I), 7-II.

https://doi.org/http://dx.doi.org/I0.26555 /bioedukatika.v5iI.5405

Jenkins, S. (1997). HOW TO WRITE A PAPER FOR A SCIENTIFIC JOURNAL.

National Research Council. (2012). A Framework for K-I2 Science Education: Practices, Crosscutting, Concepts, and core ideas. Committee on a Conceptual Framework for New K-I2 Science Education Standards.
Board on Science Education, Division of Behavioral and Social Sciences and Education. Washington, DC: The National Academies Press.

Pelger, S., \& Nilsson, P. (2016). Popular Science Writing to Support Students' Learning of Science and Scientific Literacy. Research in Science Education, 46(3), 439-456. https://doi.org/IO.I007/s I I I65-0I5-9465y

Pelger, S., \& Santesson, S. (2012). Communication training that facilitates subject understanding. In Pedagogiska Inspirationskonferens. Lund: LUNDS TEKNISKA HÖGSKOLA.

Pelger, S., Santesson, S., \& Josefsson, G. (2009). Science students writing popular science. Lund: Lund University.

Sanders-Reio, J., Alexander, P. A., Reio, T. G., \& Newman, I. (20I4). Do students' beliefs about writing relate to their writing self-efficacy, apprehension, and performance? Learning and Instruction, 33, I-I I. https://doi.org/I0.I0I6/J.LEARNINSTR UC.20I4.02.00I

Setiono. (2016). Optimalisasi Penguasaan Konsep, Kemampuan Berinkuiri Dan Sikap Ilmiah Mahasiswa Melalui Modul Berbasis Inkuiri. Biosfer: Jurnal Biologi dan Pendidikan Biologi, I(I), IO-I6.

Tonissen, K. F., Lee, S. E., Woods, K. J., \& Osborne, S. A. (20I4). Development of scientific writing skills through activities embedded into biochemistry and molecular biology laboratory courses. International Journal of Innovation in Science and Mathematics Education, 22(4).

Walsh, K. (2010). The importance of writing skills: Online tools to encourage success.

Ziker, C. (2014). A Content Comparison Analysis of the Next Generation Science Standards and the Michigan Science Standards. Menlo Park, CA: SRI International. 